\title{
NON-BASAL SLIP AS A MAJOR DEFORMATION PROCESS IN THE GREEP OF POLYGRYSTALLINE ICE
}

\author{
By W. J. McG. Tegart* \\ (Department of Materials Science and Materials Research Center, $\uparrow$ \\ The Technological Institute, Northwestern University, Evanston, Illinois, U.S.A.)
}

\begin{abstract}
Published data on the creep of polycrystalline ice and crystals oriented for non-basal slip are discussed in terms of theories of prismatic slip in hexagonal metals. It is concluded that creep of polycrystalline ice near the melting point is controlled by non-basal slip but a decision on the exact mechanism of slip cannot be made on the basis of available data.
\end{abstract}

RÉsumé. On discute les données publiées sur le fluage de la glace polycristalline et des cristaux de glace orientés pour un glissement qui n'a pas lieu dans le plan de base, en comparaison avec le glissement prismatique (glissement sur les plans perpendiculaires aux plans de base) des métaux du système hexagonal. On conclue que le fluage de la glace polycristalline près du point de fusion est sous la dépendance d'un glissement qui ne se fait pas dans le plan de base, mais on ne peut pas décider du mécanisme exact de glissement sur la base des données disponibles.

Zusammenfassung. Veröffentlichte Werte über die Kriechvorgänge in polykristallinem Eis und in Kristallen mit Orientierungen für nicht-basales Gleiten werden nach dem Muster der prismatischen Gleitvorgänge in hexagonalen Metallen behandelt. Man kann schliessen, dass das Kriechen polykristallinen Eises nahe am Schmelzpunkt durch nicht-basales Gleiten bestimmt wird; doch genügen die verfügbaren Daten nicht für eine präzise Beschreibung des Gleitmechanismus.

ThE creep of ice has been studied for many years both in the laboratory and in the field. However, although considerable data are available, only a small fraction of these are useful for determining the mechanism of the creep process and relatively little effort has been made to interpret these data in terms of modern ideas of the plastic deformation of solids.

Recently Weertman ( $19^{6} 3$ ) has discussed the creep data for ice single crystals oriented for basal slip due to Steinemann (1954) and Butkovitch and Landauer (1958) in terms of a dislocation damping mechanism due to Schoeck (I956) and Eshelby (I96I), and of a dislocation climb mechanism due to Weertman (I957[a]). Both mechanisms predict creep rates which agree within an order of magnitude with the experimental data but Weertman favors the former since it predicts the experimentally observed stress dependence.

At a given stress, the creep of polycrystalline ice is $\mathrm{IO}^{2}$ to $1 \mathrm{O}^{3}$ times slower than that of single crystals oriented for basal slip and Weertman suggests that this is due to the resolved shear stress on the basal plane of any grain in a polycrystalline aggregate being smaller than the applied stress. However, the observation of Butkovitch and Landauer that crystals oriented to suppress basal slip gave creep rates similar to those of polycrystals for similar stresses at the same temperature is so striking an analogy to the observations of Gilman (1956) on high temperature deformation of zinc that an alternative suggestion is worth examination. This note seeks to show that creep of polycrystalline ice near the melting point is controlled by non-basal slip in the crystals that are oriented with their basal planes parallel to the stress axis.

The concept of non-basal slip as an important deformation mode in ice receives support from the recent experimental observation of Muguruma (1963) and Muguruma and Higashi ( 1963 ) showing that slip can occur on $\left\{\mathrm{II}_{\overline{2}} 2\right\}$ and $\left\{\mathrm{IO}_{\overline{\mathrm{I}} \mathrm{O}}\right\}$ planes as well as on the basal plane.

In the case of zinc, the steady-state rate for prismatic slip in single crystals was found by Gilman ( 1956$)$ to be related to stress and temperature as:

$$
\dot{\epsilon}=A \sigma^{3} \exp \left(-\frac{3^{8,000}}{R T}\right)
$$

* Permanent address: Department of Metallurgy, University of Sheffield, England.

$\dagger$ The research upon which this paper is based was supported by the Advanced Research Projects Agency of the Department of Defense, through the Northwestern University Materials Research Center. 
where $\dot{\epsilon}$ is the steady-state creep rate, $A$ is a constant, $\sigma$ the applied stress, $R$ is the gas constant and $T$ is the temperature in ${ }^{\circ} \mathrm{K}$. A similar relation has also been observed by Gilman (I96r) for prismatic slip in cadmium single crystals with the stress exponent $n=2 \cdot 75$ and the activation energy for creep $Q=29,200 \mathrm{cal}$./mole. Further, work on the creep of polycrystalline zinc (Tegart and Sherby, I958), magnesium (Tegart, I96 I) and cadmium (private communication from J. E. Flinn, jr.) over the absolute temperature range 0.5 to $0.9 T_{\mathrm{m}}$, where $T_{\mathrm{m}}$ is melting temperature, has shown that both the activation energy for creep and the stress exponent change gradually from those identifiable with non-basal slip above $0 \cdot 75 \mathcal{T}_{\mathrm{m}}$ to those identifiable with self-diffusion below $0.65 T_{\mathrm{m}}$.

For ice, the temperature dependence of the creep rate of crystals oriented for non-basal slip has not been determined but the reported value of $n=2 \cdot 96$ is in agreement with the observations on zinc and cadmium. Observations on polycrystalline ice are conflicting and it is difficult to assign a definite value for $n$ and $Q$ (see, for example, Glen, 1958, 1963). It has been pointed out by Flinn in a private communication that the ratio of the activation energy for non-basal slip to the melting temperature is fairly constant for the hexagonal metals at $55 \mathrm{cal} . /{ }^{\circ} \mathrm{K}$. in contrast to the ratio of $39 \mathrm{cal} . /{ }^{\circ} \mathrm{K}$. for the ratio of the activation energy for dislocation climb to melting temperature which is to be expected from the identification of the activation energy for dislocation climb with that for self diffusion. If we extend this correlation to ice, then we predict a value of $10,600 \mathrm{cal} . / \mathrm{mole}$ for a dislocation climb process, similar to that suggested by Weertman ( 1963$)$, and a value of $\mathrm{I}_{5}, \mathrm{ooo}$ cal./mole for a non-basal slip process, similar to that suggested by Butkovitch and Landauer.

Two mechanisms have been proposed for prismatic slip in hexagonal metals. The first, due to Weertman ( $1957[\mathrm{~b}]$ ) is based on overcoming a large Peierls stress on the prismatic plane, while the second, due to Friedel (1959) is based on thermally activated cross-slip from the basal plane into the prismatic plane. The former yields a stress exponent of 2.5 at low stresses while the latter gives an exponent of 2 . It is possible to calculate activation energies for the two mechanisms but both depend on the assumed width of the dislocations since this determines the Peierls stress in the former case and the constriction energy in the latter case.

One way to use Weertman's model for the case of ice is to take the value of $Q$ as predicted empirically and see whether a reasonable value of the Peierls stress emerges after substitution in his expression for $Q$ which is:

$$
Q \simeq(4 d b / \pi)(2 \mu \tau d b / 5 \pi)^{\frac{1}{2}}
$$

where $d$ is the distance between Peierls hills, $b$ is the Burgers vector, $\mu$ is the shear modulus and $\tau$ is the Peierls stress. Using $\mu=3 \times \mathrm{ro}^{10} \mathrm{dyne} / \mathrm{cm}^{2}, a=4 \cdot 5 \AA, c=7 \cdot 35 \AA$, the calculated value of $\tau$ is $3 \times 10^{10}$ dyne $/ \mathrm{cm}^{2}$ which is similar to that calculated for zinc from the experimental value of $Q$.

Assuming then that the predicted $Q$ is reasonable, we can calculate the creep rate from Weertman's equation which simplifies to:

$$
\dot{\epsilon}=10^{-10} \sigma^{2 \cdot 5} \exp \left(-\frac{15,000}{R T}\right)
$$

where all the quantities are in c.g.s. units. This predicts a rate of $10^{-7} / \mathrm{sec}$. at $\sigma=\mathrm{I} \mathrm{kg.} / \mathrm{cm} .^{2}$ at $-5^{\circ} \mathrm{C}$. in reasonable agreement with the experimental value of $\mathrm{IO}^{-8} / \mathrm{sec}$.

In Friedel's model, the activation energy consists of two terms as

$$
Q=U_{\mathrm{c}}+\frac{x(2 x)^{\frac{1}{2}} \mu^{2} b^{2}}{3^{\sigma}}
$$

where $U_{\mathrm{c}}$ is the constriction energy and $x$ is the ratio of the energy gained per unit length in dissociation to the line tension of undissociated dislocation, about $\mathrm{IO}^{-2}$ for reasonable values. If the dislocation is undissociated, $U_{\mathrm{c}}$ can be neglected and the second term is dominant while 
if the dislocation is dissociated the reverse is true. Similar calculations to those of Gilman (1956) indicate that the dislocations in ice are probably undissociated and thus use of the second term gives $Q \simeq \mathrm{I} 4,000 \mathrm{cal} . /$ mole for $\sigma=\mathrm{I} \mathrm{kg} . / \mathrm{cm} .^{2}$ in reasonable agreement with the empirically predicted value. The creep rate can then be calculated from Friedel's equation which simplifies to a similar expression to that of equation (3), namely:

$$
\dot{\epsilon} \simeq \mathrm{IO}^{-8} \sigma^{2} \exp \left(-\frac{\mathrm{I} 4, \mathrm{OoO}}{R T}\right)
$$

where all the quantities are again in c.g.s. units. For $\sigma=\mathrm{I} \mathrm{kg.} / \mathrm{cm} .^{2}$ and $-5{ }^{\circ} \mathrm{C}$., this also gives a creep rate of $10^{-7} / \mathrm{sec}$.

Thus either mechanism can describe the observed creep behavior of ice single crystals oriented for non-basal slip although possibly more weight can be given to Friedel's mechanism in view of the recent observation of cross-slip in ice by Muguruma.

In the case of the zinc polycrystals used by Gilman, the stress required to produce a given rate at a given temperature is about 30 per cent lower than that for crystals oriented for prismatic slip. Examination of the data of Butkovitch and Landauer for ice indicates a similar but smaller trend. This stress difference arises because only a fraction of the grains in the aggregate are oriented for non-basal slip and thus initially the grains oriented for basal slip will deform to accommodate the applied load. However, as deformation proceeds, the load on the less favorably oriented grains increases until the local stress is sufficient to activate non-basal slip in these grains which then control the rate of deformation. Because of local inhomogeneities of strain, minor deformation modes, e.g. folding and boundary migration, occur as described by Gold (1963). From his observations, he ascribes a minor role to non-basal slip in contrast to the viewpoint expressed here.

From the above discussion, the creep of polycrystalline ice near the melting point is considered to be controlled by non-basal slip and hence the creep rate can be expressed by an equation similar to that of equation (3) or (5), depending on the exact mechanism of the slip process, with a factor in the pre-exponential term to allow for the distribution of grain orientations, i.e. a factor dependent on texture. Further, by analogy with the results on hexagonal metals, we expect a change in the rate-controlling process to that of dislocation climb at temperatures around $-65^{\circ} \mathrm{C}$. to $-100^{\circ} \mathrm{C}$. with a change in stress exponent to around 4.5 and a change in activation energy to around 10,500 cal./mole. Clearly further careful experimental work is desirable to check these ideas.

I wish to thank Professor J. Weertman for his interest and encouragement.

MS. received ${ }_{15}$ October 1963

\section{REFERENGES}

Butkovich, T. R., and Landauer, J. K. 1958. The flow law for ice. Union Géodésique et Géophysique Internationale. Association Internationale d'Hydrologie Scientifique. Symposium de Chamonix, 16-24 sept. 1958, p. 318-27.

Eshelby, J. D. I961. Dislocations in visco-elastic materials. Philosophical Magazine, Eighth Ser., Vol. 6, No. 68, p. $953-63$.

Friedel, J. 1959. Dislocation interactions and internal strains. (In Rassweiler, G. M., and Grube, W. L., ed. Internal stresses and fatigue in metals. Amsterdam, Elsevier Publishing Co., p. 220-62.)

Gilman, J. J. 1956. Plastic anisotropy of zinc monocrystals. Transactions of the American Institute of Mining and Metallurgical Engineers, Vol. 206, p. $1326-36$.

Gilman, J. J. I961. Prismatic glide in cadmium crystals. Transactions of the American Institute of Mining and Metallurgical Engineers, Vol. 221 , p. $456-57$.

Glen, J. W. 1958. The mechanical properties of ice. I. The plastic properties of ice. Advances in Physics, Vol. 7 , No. 26 , p. $254-65$.

Glen, J. W. ${ }_{1963}$. The rheology of ice. (In Kingery, W. D., ed. Ice and snow; properties, processes, and applications: proceedings of a conference held at the Massachusetts Institute of Technology, February $12-16,{ }_{1962 .}$. Cambridge, Mass., The M.I.T. Press, p. $3^{-7 .)}$ 
Gold, L. W. 1963. Deformation mechanisms in ice. (In Kingery, W. D., ed. Ice and snow; properties, processes, and applications: proceedings of a conference held at the Massachusetts Institute of Technology, February 12-16, 1962. Cambridge, Mass., The M.I.T. Press, p. 8-27.)

Muguruma, J. 1963. Etch pits on prism planes of plastically deformed ice crystals. Fournal of the Faculty of Science, Hokkaido University, Ser. 2, Vol. 6, No. 1, p. 1 1-22.

Muguruma, J., and Higashi, A. I 963 . Observations of etch channels on the (0001) plane of ice crystals produced by non-basal glide. Fournal of the Physical Society of Japan, Vol. 18, No. 9, p. 1261-69.

Schoeck, G. I956. Moving dislocations and solute atoms. Physical Review, Second Ser., Vol. 102, No. 6, p. I458-59.

Steinemann, S. 1954. Results of preliminary experiments on the plasticity of ice crystals. Fournal of Glaciology, Vol. 2, No. I6, p. 404-13.

Tegart, W. J. M. I96r. Activation energies for high temperature creep of polycrystalline magnesium. Acta Metallurgica, Vol. 9, No. 6, p. 614-17.

Tegart, W. J. M., and Sherby, O. D. 1958. Activation energies for high temperature creep of polycrystalline zinc. Philosophical Magazine, Eighth Ser., Vol. 3, No. 35, p. 1287-96.

Weertman, J. 1957[a]. Steady-state creep through dislocation climb. Journal of Applied Physics, Vol. 28, No. 3, p. $362-64$.

Weertman, J. 1957[b]. Steady-state creep of crystals. Journal of Applied Physics, Vol. 28, No. 10, p. $1185-89$.

Weertman, J. 1963. The Eshelby-Schoeck viscous dislocation damping mechanism applied to the steady-state creep of ice. (In Kingery, W. D., ed. Ice and snow; properties, processes, and applications: proceedings of a conference held at the Massachusetts Institute of Technology, February 12-16, 1962. Cambridge, Mass., The M.I.T. Press, p. 28-33.) 